\title{
A longitudinal survey of adult spine and peripheral nerve case entries during neurosurgery residency training
}

\author{
Presented at the 2018 AANS/CNS Joint Section on Disorders of the Spine and Peripheral Nerves \\ Nitin Agarwal, MD, Michael D. White, BS, and D. Kojo Hamilton, MD \\ Department of Neurological Surgery, University of Pittsburgh Medical Center, Pittsburgh, Pennsylvania
}

OBJECTIVE Currently, there is a lack of research assessing residents' operative experience and caseload variability. The current study utilizes data from the Accreditation Council for Graduate Medical Education (ACGME) case log system to analyze national trends in neurosurgical residents' exposure to adult spinal procedures.

\begin{abstract}
METHODS Prospectively populated ACGME resident case logs from 2013 to 2017 were retrospectively reviewed. The reported number of spinal procedures was compared to the ACGME minimum requirements for each surgical category pertaining to adult spine surgery. A linear regression analysis was conducted to identify changes in operative caseload by residents graduating during the study period, as well as a one-sample t-test using IBM SPSS software to compare the mean number of procedures in each surgical category to the ACGME required minimums.
\end{abstract}

RESULTS A mean of 427.42 total spinal procedures were performed throughout residency training for each of the 877 residents graduating between 2013 and 2017. The mean number of procedures completed by graduating residents increased by $19.96\left(r^{2}=0.95\right)$ cases per year. The number of cases in every procedural subspecialty, besides peripheral nerve operations, significantly increased during this time. The two procedural categories with the largest changes were anterior and posterior cervical approaches for decompression/stabilization, which increased by $8.78 \%$ per year $\left(r^{2}=\right.$ $0.95)$ and $9.04 \%$ per year $\left(r^{2}=0.95\right)$, respectively. There was also a trend of increasing cases logged for lead resident surgeons and a decline in cases logged for senior resident surgeons. Residents' mean caseloads during residency were found to be vastly greater than the ACGME required minimums: residents performed at least twice as many procedures as the required minimums in every surgical category.

CONCLUSIONS Graduating neurosurgical residents reported increasing case volumes for adult spinal cases during this 5-year interval. An increase in logged cases for lead resident surgeons as opposed to senior resident surgeons indicates that residents were logging more cases in which they had a more critical role in the procedure. Moreover, the average resident was noted to perform more than twice the number of procedures required by the ACGME in every surgical category, indicating that neurosurgical residents are getting greater exposure to spine surgery than expected. Given the known correlation between case volume and improved surgical outcomes, this data demonstrates each graduating neurosurgical residency class experiences an augmented training in spine surgery.

https://thejns.org/doi/abs/10.3171/2018.3.SPINE171370

KEYWORDS Accreditation Council for Graduate Medical Education; case logs; residency; spine; neurological surgery; ACGME; spinal procedures

$\mathrm{G}$ RADUATING neurosurgical residents must be competent in a vast array of spine surgery procedures. To gain this competency, residents must have extensive exposure to spine surgery throughout their training. To understand how well graduating neurosurgeons are being trained, and to continuously improve residency train- ing, it is essential to evaluate residents' surgical experience and recent trends in exposure to spine surgery. Identifying gaps in surgical experience, variability in case volumes among graduates, and factors that can impact exposure to spinal procedures can allow for improvement in the education provided to residents, particularly in spine surgery.

ABBREVIATIONS ACDF = anterior cervical approach for decompression/stabilization and fusion; $A C G M E=$ Accreditation Council for Graduate Medical Education; $P C D F$ = posterior cervical approach for decompression/stabilization and fusion.

SUBMITTED December 10, 2017. ACCEPTED March 14, 2018.

INCLUDE WHEN CITING Published online July 20, 2018; DOI: 10.3171/2018.3.SPINE171370. 
TABLE 1. Number of graduating neurosurgical residents and residency programs for each year included in the study

\begin{tabular}{ccc}
\hline Year & No. of Graduating Residents & No. of Programs \\
\hline 2013 & 178 & 90 \\
\hline 2014 & 159 & 91 \\
\hline 2015 & 168 & 93 \\
\hline 2016 & 186 & 94 \\
\hline 2017 & 186 & 97 \\
\hline
\end{tabular}

There has been a well-documented association between higher case volumes for surgeons and positive surgical outcomes for patients. ${ }^{9,11}$ This volume-outcome relationship suggests that higher spinal case volumes for residents will lead to more skilled and adept spine surgeons. The Accreditation Council for Graduate Medical Education (ACGME) applies this model to neurosurgical residency training and has developed a required minimum number of procedures within each facet of spine surgery needed for graduation. The required minimums set forth by the $\mathrm{ACMGE}^{2}$ aim to ensure that residents receive a diverse and comprehensive training in all aspects of spine surgery. The current study utilizes this ACGME case log system to analyze national trends in neurosurgical resident exposure to adult spinal procedures.

\section{Methods}

Prospectively populated ACGME resident case logs containing de-identified data from a total of 877 residents graduating between 2013 and 2017 were retrospectively reviewed. These reports contained the average number of procedures performed in each surgical category and the level of the resident (lead resident surgeon, senior resident surgeon, and assistant resident surgeon) for each year. Of note, the resident level of case involvement is defined by the ACGME in the following manner. The role of assistant resident surgeon is defined as "participating in positioning, sterile preparation, placement of monitoring devices, microscope preparation, participation in the initial (opening) or final (closing) portions of the case, and/or assisting the resident or staff surgeon(s)." The role of senior resident surgeon includes aspects from the assistant resident surgeon role but "must include participation in the surgical procedure between opening and closing." Finally, the lead resident surgeon role contains aspects of the prior two roles but "must include participation in the critical portion of the case."

Table 1 illustrates the number of neurosurgery programs and graduating residents for each year included in the study. These logs were evaluated to determine trends in residency experience with adult spinal procedures. The reports divided the various spine procedures into procedural categories, which are included in Table 2. The reported number of spinal procedures was compared to the ACGME minimum requirements for each surgical category pertaining to adult spine surgery. A linear regression analysis was conducted to identify changes in operative caseload by residents graduating during the study period,
TABLE 2. Linear regression results for each of the 5 surgical categories and total spine procedures

\begin{tabular}{|c|c|c|c|c|}
\hline Category & $\begin{array}{c}\text { Mean } \\
\text { No. of } \\
\text { Procedures }\end{array}$ & $\begin{array}{c}\text { Change } \\
\text { (procedures/yr) }\end{array}$ & $r^{2}$ & p Value \\
\hline ACDF & 72.66 & 6.38 & 0.95 & $0.0046^{*}$ \\
\hline PCDF & 56.98 & 5.15 & 0.95 & $0.0048^{*}$ \\
\hline Lumbar discectomy & 125.70 & 3.62 & 0.79 & $0.0452 \dagger$ \\
\hline Thoracolumbar fusion & 145.92 & 4.05 & 0.87 & $0.0207 \dagger$ \\
\hline Peripheral nerve & 26.20 & 0.81 & 0.52 & 0.1683 \\
\hline Total spine ops & 427.42 & 19.96 & 0.95 & $0.0042^{*}$ \\
\hline
\end{tabular}

as well as a one-sample t-test using SPSS software (IBM Corp.) to compare the mean number of procedures in each surgical category to the ACGME required minimums.

\section{Results}

A mean of 427.42 total spinal procedures were performed throughout residency training for each of the 877 residents graduating between 2013 and 2017. The mean number of procedures completed by graduating residents increased by $19.96\left(\mathrm{r}^{2}=0.95\right)$ cases per year, with every surgical category, except for peripheral nerve procedures, significantly increasing during this time (Table 2). Peripheral nerve operations demonstrated a slight upward trend; however, this increase was not found to be statistically significant. The total number of spine procedures performed by graduating residents ranged from 385.80 in 2013 to 460.80 in 2017. The mean number of total procedures each year, as well as the change in total procedures throughout the study period, is illustrated in Fig. 1. The two surgical categories with the largest changes were anterior cervical approach for decompression/stabilization and fusion (ACDF) and posterior cervical approach for decompression/stabilization and fusion (PCDF), which increased by 6.38 procedures per year $\left(\mathrm{r}^{2}=0.95\right)$ and 5.15 procedures per year $\left(r^{2}=0.95\right)$, respectively. This change correlates to an $8.78 \%$ increase per year for ACDF and a 9.04\% increase per year for PCDF.

The procedures with the highest volume were thoracolumbar fusion, lumbar discectomy, and ACDF, with means of $145.92,125.70$, and 72.66 procedures per year, respectively. These comprised $34.14 \%, 29.41 \%$, and $17.00 \%$ of all spine procedures performed, respectively. It was found that case volumes for every surgical category, except for peripheral nerve procedures, significantly increased on average throughout the study period.

Trends in operative volume were also analyzed based on resident level: lead resident surgeon, senior resident surgeon, and assistant resident surgeon. The largest observed change was at the level of lead resident surgeon, which demonstrated an average increase of 56.71 procedures per year $\left(\mathrm{r}^{2}=0.978\right)$. This increase in lead resident surgeon procedures was accompanied by a decline in senior resident surgeon procedures, which decreased an average of 


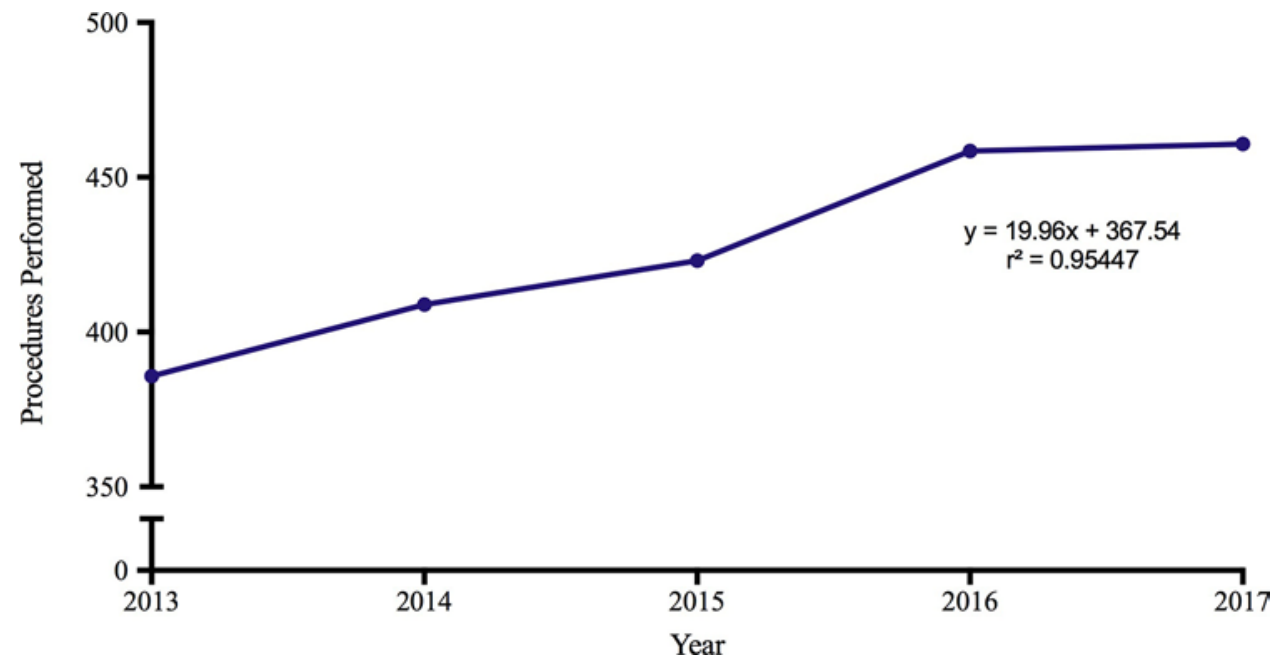

FIG. 1. National means for the total number of spinal procedures for graduating residents. Figure is available in color online only.

36.70 procedures per year $\left(r^{2}=0.948\right)$. Finally, assistant resident surgeon procedures also demonstrated a slight incline of 1.71 procedures per year $\left(r^{2}=0.876\right)$. These trends are illustrated in Fig. 2.

Overall, residents' mean caseloads during residency were found to be vastly greater than the ACGME required minimums: residents performed at least twice as many procedures as the required minimums in every surgical category (Fig. 3). The ACGME required minimum procedures are illustrated within Table 3 . The average graduating resident in 2017 performed 6.7 times the required minimum for thoracolumbar fusion procedures.

\section{Discussion}

\section{Trends in Spine Surgery in the US}

This study found that total spine procedures performed by graduating US residents has continuously risen from 2013 to 2017. This includes a significant increase in every surgical category, except for peripheral nerve procedures, pertaining to the spine. In other surgical specialties, there have been mixed findings regarding case volumes for various surgical procedures. Previous studies have shown that general surgery residents have experienced a decline in pediatric and trauma cases, whereas orthopedic surgery residents have shown a rise in trauma and oncology cases..$^{7,10,14,15}$ Neurosurgical residents' case volumes in spine surgery have demonstrated upward trends during this 5-year period.

A previous survey revealed that half of the responding neurosurgeons did not feel they were given adequate training in peripheral nerve operations during residency. Additionally, $76.5 \%$ of neurosurgeons were found to refer complex peripheral nerve cases to other surgeons. ${ }^{18}$ With a perceived deficit in peripheral nerve training, it is worrisome that this was the only procedure that did not demonstrate a significant increase. To further enhance resident competency in peripheral nerve operations, additional methods of training may need to be implemented. One area of surgical training that has been shown to augment surgical skill is that of surgical simulation. In the field of general surgery, surgical simulation has been shown to improve surgical skills and improve performance in the operating room. A randomized trial demonstrated that gallbladder dissection operations were $29 \%$ faster and were 6 times less likely to have errors occur when performed by groups that trained with surgical simulation. ${ }^{21}$ Simulation training has also been shown to improve performance in a range of neurosurgical procedures, including spinal surgery. ${ }^{17}$ Although the caseload for peripheral nerve operations did not significantly increase, supplementing operating room experience with surgical simulation training can be one method to ensure that graduating residents are competent in these procedures.

Since overall procedures have increased and residents are assuming a more critical role in surgical procedures, as demonstrated by a higher number of cases logged as the lead resident surgeon, it can be concluded that neurosurgical residents may be gaining more extensive training

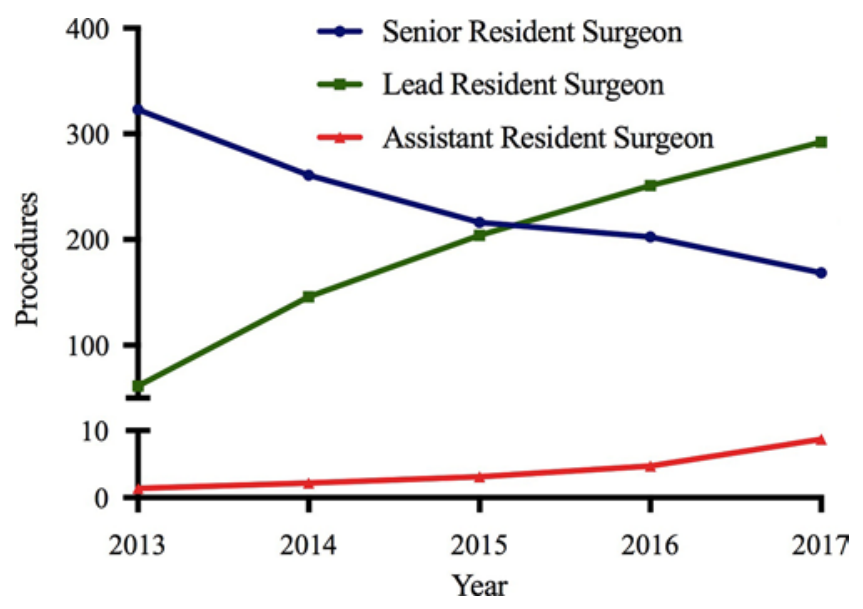

FIG. 2. Mean number of procedures logged by each level of resident plotted from 2013 to 2017. Senior resident surgeon, $y=-36.7 x+344.30$ $\left(r^{2}=0.9476\right)$; lead resident surgeon, $y=56.71 x+20.81\left(r^{2}=0.9780\right)$; and assistant resident surgeon, $y=1.71 x-1.11\left(r^{2}=0.8758\right)$. Figure is available in color online only. 


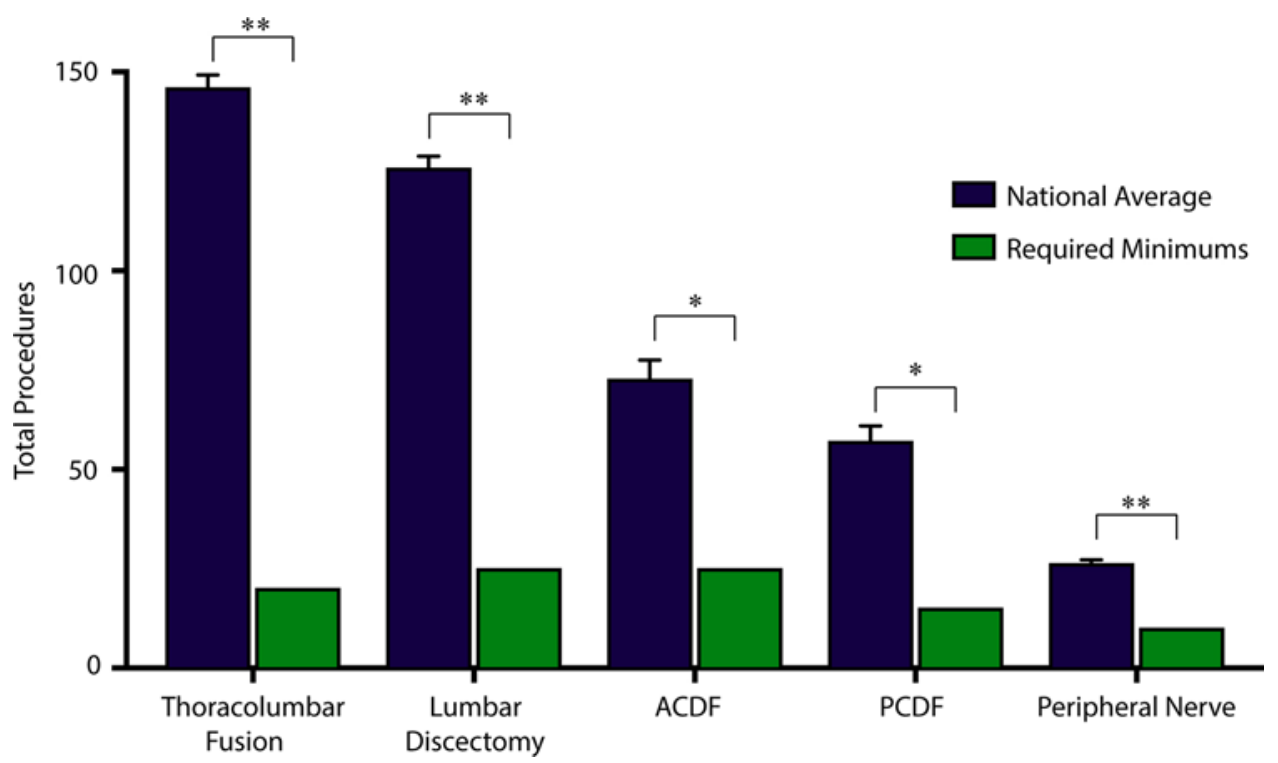

FIG. 3. Mean number of procedures performed nationally by graduating residents, plotted with the standard error of the mean, compared to the required minimum for each surgical category. Thoracolumbar fusion procedures had a mean of $145.95 \pm 3.07$ and a required minimum of 20. Lumbar discectomy procedures had a mean of $125.70 \pm 2.89$ and a required minimum of 25 . Anterior cervical approach for decompression/stabilization and fusion (ACDF) procedures had a mean of $72.66 \pm 4.62$ and a required minimum of 25. Posterior cervical approach for decompression/stabilization and fusion (PCDF) procedures had a mean of 56.98 \pm 3.73 and a required minimum of 15. Total peripheral nerve procedures had mean of $26.20 \pm 0.79$ and a required minimum of 10 . One-sample t-test: ${ }^{*} p<0.001$ and ${ }^{* *} p<0.0001$. Figure is available in color online only.

in spine surgery. There is a well-documented relationship between surgeons' surgical case volumes and patients' operative outcomes within spine surgery.,11,20 This has been demonstrated in spine surgery and in many other types of surgical specialties. ${ }^{8,13}$ For example, Schoenfeld et al. demonstrated that patients undergoing surgery for spinal metastases performed by low-volume surgeons had significantly higher odds of complications and readmissions than those performed by high-volume surgeons. ${ }^{20} \mathrm{By}$ gaining more significant exposure to spine surgery during residency training, residents will be more competent and experienced upon graduation. Additionally, Bjerrum et al. demonstrated a relationship called "procedure-to-procedure transfer." They described how trainees practicing and reaching proficiency in one laparoscopic procedure were able to reach proficiency significantly quicker in a different laparoscopic procedure than control groups. ${ }^{6}$ The idea that the skills learned in the first procedure were able to facilitate quicker progression in supplemental operations can apply to the training of neurosurgery residents. Because residents are spending more time as lead resident surgeons, the skills they learn from this more critical role during operations may facilitate quicker progression in and learning of additional procedures. Because of the volume-outcome and procedure-to-procedure transfer relationships, augmented exposure to spine surgery may have significant effects on resident competency in spine surgery upon graduation.

Neurosurgical residents are also performing significantly more spine procedures than required by the ACGME. The ACGME has a required minimum number of procedures that need to be performed in each surgical category by the time of graduation. The purpose of these minimums is to ensure that graduating residents are competent in an extensive variety of spine procedures. The results of the present study indicate that neurosurgical residents are actually performing well beyond the required minimums set forth by the ACGME (Fig. 3). For example, graduating residents are performing more than 7 times the required minimum for thoracolumbar fusions. This trend is also seen throughout the various spinal subcategories. In fact, the number of procedures performed by the average resident is at least twice the required minimum for every spinal subcategory. The significantly higher number of actual procedures being performed demonstrates that neurosurgical residents are far exceeding what the ACGME considers the required minimum for surgical competency.

An interesting observation in the present study was that thoracolumbar fusion was found to be the highest-volume spinal procedure. Rajaee et al. examined trends in spine fusion procedures and found that, from 1998 to 2008, the number of fusions performed increased at a much higher rate than other types of procedures. In addition to the rise in number of fusion procedures, they also found that inhospital mortality rates had declined. ${ }^{19}$ Fusions have risen to be one of the most frequently performed spinal procedures, and residents are certainly gaining significant exposure during training. Some possible factors that could explain the high volume of fusion procedures is the increasing size of the aging population, the development of advanced spinal fixation devices, and the increased availability of minimally invasive spine surgery. Rajaee et al. also found that the number of fusion procedures increased at a much higher rate than other spinal procedures, such as laminectomy. This rapid rise in fusions has resulted in thoracolumbar fusion procedures surpassing other common 
procedures, such as discectomy, as the most performed operation.

\section{Duty-Hour Restrictions}

The implementation of duty-hour restrictions by the ACGME in 2003 and 2011 has bolstered uncertainty as to how neurosurgical residency training will be affected. The 2003 restrictions set the limit of 80-hour work weeks for residents, and the most recent duty-hour restrictions in 2011 included additional restrictions on maximum shift length and mandatory minimum time periods between shifts. The restrictions are an effort to reduce physician fatigue and increase patient safety. However, these policies have been controversial, and many studies have reported varying effects of these restrictions on resident education. One study found that the 2011 restrictions on duty hours did not reduce mortality or surgical complication rates among surgical residents. ${ }^{4}$ In fact, another study found that $96 \%$ of program directors believe duty-hour restrictions will actually compromise patient safety because of inadequate training of neurosurgical residents. ${ }^{16}$ In terms of operative volume, another report found that the caseload of general surgery procedures considered to be "essential operations" declined after the implementations of duty-hour restrictions. ${ }^{5}$ Similar results for many aspects of resident education are evident in the literature.,12

The only spinal subspecialty that was not observed to have a significant change in number of procedures was peripheral nerve operations. During the 5-year interval for this study, there was a $9.5 \%$ increase in the number of total peripheral nerve operations; however, this increase did not reach statistical significance.

The present study has shown that the surgical caseloads for spine surgery have continued to increase despite the restrictions implemented in 2011. There has not yet been a residency class that has experienced all 7 years of residency since implementation of the restrictions; however, graduating residents are continuing to show positive trends in spine surgery caseloads even 6 years after the most recent duty-hour restrictions were put in place. These trends indicate that programs are able to expand resident operative exposure within these rules. Despite other studies finding that these restrictions negatively affect resident case volume, neurosurgical residencies have not experienced the same decline as these reports.

\section{Future Studies}

The trends observed in this study provide an opportunity for further investigation into neurosurgical resident exposure to spine surgery. Supplemental studies could examine case volume in spine procedures based on postgraduate year of residents. Further analysis could also investigate correlations between volume of spine procedures and the number of spine fellowships at various institutions. Additionally, it would be interesting to examine correlations between increased spine surgery exposure during residency and the number of applications to spine fellowships. Finally, it would be valuable to explore trends in resident exposure specifically to complex spine surgery, such as deformity or oncological procedures.
TABLE 3. Current neurological surgery case log defined case categories and required minimum numbers

\begin{tabular}{|c|c|}
\hline Defined Case Category & $\begin{array}{c}\text { Required } \\
\text { Minimum Number }\end{array}$ \\
\hline \multicolumn{2}{|l|}{ Adult Cranial } \\
\hline DC1 Craniotomy for brain tumor & 60 \\
\hline DC2 Craniotomy for trauma & 40 \\
\hline $\begin{array}{l}\text { Total vascular lesion (Combined DC3a and } \\
\text { DC3b) }\end{array}$ & 50 \\
\hline DC3a Craniotomy for intracranial vascular lesion & Must be reported \\
\hline $\begin{array}{l}\text { DC3b Endovascular therapy for tumor or vascu- } \\
\text { lar lesion }\end{array}$ & Must be reported \\
\hline DC4 Craniotomy for pain & 5 \\
\hline $\begin{array}{l}\text { DC5 Transsphenoidal sellar/parasellar tumors } \\
\text { (endoscopic and microsurgical) }\end{array}$ & 15 \\
\hline DC6 Extracranial vascular procedures & 5 \\
\hline DC7 Radiosurgery & 10 \\
\hline DC8 Functional procedures & 10 \\
\hline DC9 VP shunt & 10 \\
\hline Total Adult Cranial & 205 \\
\hline \multicolumn{2}{|l|}{ Adult Spinal } \\
\hline $\begin{array}{l}\text { DC10 Anterior cervical approaches for decom- } \\
\text { pression/stabilization }\end{array}$ & 25 \\
\hline $\begin{array}{l}\text { DC11 Posterior cervical approaches for decom- } \\
\text { pression/stabilization }\end{array}$ & 15 \\
\hline DC12 Lumbar discectomy & 25 \\
\hline DC13 Thoracic/lumbar instrumentation fusion & 20 \\
\hline DC14 Peripheral nerve procedures & 10 \\
\hline Total Adult Spinal & 95 \\
\hline \multicolumn{2}{|l|}{ Pediatric } \\
\hline DC15 Brain tumor & 5 \\
\hline DC16 Trauma (uses adult trauma codes) & 10 \\
\hline DC17 Spinal procedures & 5 \\
\hline DC18 VP shunt & 10 \\
\hline Total Pediatric & 30 \\
\hline DC19 Adult and Pediatric Epilepsy & 10 \\
\hline \multicolumn{2}{|l|}{ Critical Care } \\
\hline DC20 ICP monitor placement & 5 \\
\hline DC21 External ventricular drain & 10 \\
\hline DC22 VP shunt tap/programming & 10 \\
\hline DC23 Cervical spine traction & 5 \\
\hline DC25 CVP line placement & 10 \\
\hline DC26 Airway management & 10 \\
\hline DC27 Arterial line placement & 10 \\
\hline Total Critical Care & 60 \\
\hline Total All Defined Case Categories & 400 \\
\hline \multicolumn{2}{|l|}{ Reportable but Non-Tracked Categories } \\
\hline \multicolumn{2}{|l|}{ Arteriography } \\
\hline Stereotactic frame placement & \\
\hline
\end{tabular}

$\mathrm{CVP}=$ central venous pressure; $\mathrm{ICP}=$ intracranial pressure; $\mathrm{VP}=$ ventriculoperitoneal.

Copyright 2018 Accreditation Council for Graduate Medical Education. Published with permission. Retrieved March 1, 2018: https://www.acgme.org/ Portals/O/PFAssets/ProgramResources/160_Neurological_Surgery_Defined Case_Categories_and_Required_Minimum_Numbers.pdf. 


\section{Conclusions}

Graduating neurosurgical residents logged increasing case volumes for adult spinal cases during this 5-year period from 2013 to 2017. However, peripheral nerve operations did not demonstrate any significant change. Additional training methods, such as surgical simulation, could be utilized to ensure adequate training in this area of neurosurgery. We also found a trend of increasing procedures logged for lead resident surgeons and a decline in procedures for senior resident surgeons, indicating that residents are logging more procedures in which they have a more critical role in the operation. The average resident was noted to perform more than twice the number of procedures required by the ACGME in every surgical category, indicating that neurosurgical residents are gaining greater exposure to spine surgery than expected. Additionally, case volumes continued to rise despite the duty-hour restrictions implemented by the ACGME in 2011. Given the known correlation between case volume and improved surgical outcomes, these data demonstrate each graduating neurosurgical residency class experiences an augmented training in spine surgery.

\section{References}

1. Accreditation Council for Graduate Medical Education: Case Log Guidelines. Chicago: ACGME Review Committee for Neurological Surgery, 2017 (https:// www.acgme.org/Portals/0/PFAssets/ProgramResources/ Case_Log_Guidelines.pdf?ver=2016-04-19-140246-217) [Accessed April 10, 2018]

2. Accreditation Council for Graduate Medical Education: Neurological Surgery Case Log Defined Case Categories and Required Minimum Numbers. Chicago: ACGME Review Committee for Neurological Surgery, 2017 (https:// www.acgme.org/Portals/0/PFAssets/ProgramResources/160_ Neurological_Surgery_Defined_Case_Categories_and Required_Minimum_Numbers.pdf) [Äccessed April 10, 2018]

3. Ahmed N, Devitt KS, Keshet I, Spicer J, Imrie K, Feldman L, et al: A systematic review of the effects of resident duty hour restrictions in surgery: impact on resident wellness, training, and patient outcomes. Ann Surg 259:1041-1053, 2014

4. Anderson JE, Goodman LF, Jensen GW, Salcedo ES, Galante JM: Restrictions on surgical resident shift length does not impact type of medical errors. J Surg Res 212:8-14, 2017

5. Bell RH Jr, Biester TW, Tabuenca A, Rhodes RS, Cofer JB, Britt LD, et al: Operative experience of residents in US general surgery programs: a gap between expectation and experience. Ann Surg 249:719-724, 2009

6. Bjerrum F, Sorensen JL, Konge L, Rosthøj S, Lindschou J, Ottesen B, et al: Randomized trial to examine procedure-toprocedure transfer in laparoscopic simulator training. $\mathbf{B r} \mathbf{J}$ Surg 103:44-50, 2016

7. Blood TD, Gil JA, Born CT, Daniels AH: Variability in trauma case volume in orthopedic surgery residents. Orthop Rev (Pavia) 9:6967, 2017

8. Boudourakis LD, Wang TS, Roman SA, Desai R, Sosa JA: Evolution of the surgeon-volume, patient-outcome relationship. Ann Surg 250:159-165, 2009

9. Dasenbrock HH, Clarke MJ, Witham TF, Sciubba DM, Gokaslan ZL, Bydon A: The impact of provider volume on the outcomes after surgery for lumbar spinal stenosis. Neurosurgery 70:1346-1354, 2012

10. Drake FT, Van Eaton EG, Huntington CR, Jurkovich GJ, Aarabi S, Gow KW: ACGME case logs: Surgery resident experience in operative trauma for two decades. J Trauma Acute Care Surg 73:1500-1506, 2012

11. Farjoodi P, Skolasky RL, Riley LH: The effects of hospital and surgeon volume on postoperative complications after lumbar spine surgery. Spine (Phila Pa 1976) 36:2069-2075, 2011

12. Feanny MA, Scott BG, Mattox KL, Hirshberg A: Impact of the 80-hour work week on resident emergency operative experience. Am J Surg 190:947-949, 2005

13. Finks JF, Osborne NH, Birkmeyer JD: Trends in hospital volume and operative mortality for high-risk surgery. $\mathbf{N}$ Engl J Med 364:2128-2137, 2011

14. Gow KW, Drake FT, Aarabi S, Waldhausen JH: The ACGME case log: general surgery resident experience in pediatric surgery. J Pediatr Surg 48:1643-1649, 2013

15. Hinds RM, Rapp TB, Capo JT: Orthopedic oncology caseload among orthopedic surgery residents. J Cancer Educ 33:293-297, 2018

16. Jagannathan J, Vates GE, Pouratian N, Sheehan JP, Patrie J, Grady MS, et al: Impact of the Accreditation Council for Graduate Medical Education work-hour regulations on neurosurgical resident education and productivity. J Neurosurg 110:820-827, 2009

17. Kirkman MA, Ahmed M, Albert AF, Wilson MH, Nandi D, Sevdalis N: The use of simulation in neurosurgical education and training. A systematic review. J Neurosurg 121:228246, 2014

18. Maniker A, Passannante M: Peripheral nerve surgery and neurosurgeons: results of a national survey of practice patterns and attitudes. J Neurosurg 98:1159-1164, 2003

19. Rajaee SS, Bae HW, Kanim LE, Delamarter RB: Spinal fusion in the United States: analysis of trends from 1998 to 2008. Spine (Phila Pa 1976) 37:67-76, 2012

20. Schoenfeld AJ, Ferrone ML, Sturgeon DJ, Harris MB: Volume-outcome relationship in surgical interventions for spinal metastases. J Bone Joint Surg Am 99:1753-1759, 2017

21. Seymour NE, Gallagher AG, Roman SA, O'Brien MK, Bansal VK, Andersen DK, et al: Virtual reality training improves operating room performance: results of a randomized, double-blinded study. Ann Surg 236:458-464, 2002

\section{Disclosures}

The authors report no conflict of interest concerning the materials or methods used in this study or the findings specified in this paper.

\section{Author Contributions}

Conception and design: Agarwal, Hamilton. Acquisition of data: Agarwal, White. Analysis and interpretation of data: Agarwal, White. Drafting the article: Agarwal, White. Critically revising the article: Agarwal, Hamilton. Reviewed submitted version of manuscript: all authors. Approved the final version of the manuscript on behalf of all authors: Agarwal. Statistical analysis: White. Administrative/technical/material support: Hamilton. Study supervision: Agarwal, Hamilton.

\section{Supplemental Information}

\section{Previous Presentations}

Presented at the 34th Annual Meeting of the Section on Disorders of the Spine and Peripheral Nerves, Orlando, Florida, March 14-17, 2018.

\section{Correspondence}

Nitin Agarwal: University of Pittsburgh Medical Center, Pittsburgh, PA. agarwaln@upmc.edu. 